\title{
Gliosarcoma with Osteosarcomatous Component: A Case Report and Short Review Illustration
}

\author{
Yanming Chen \\ Second Affiliated Hospital of Soochow University \\ Sujuan Zhou \\ Suzhou Sano Precision Medicine Ltd \\ Xuelan Zhou \\ Second Affiliated Hospital of Soochow University \\ Xiaoxiao Dai \\ Second Affiliated Hospital of Soochow University \\ Liping Wang \\ Second Affiliated Hospital of Soochow University \\ Ping Chen \\ Suzhou Sano Precision Medicine Ltd \\ Shengbin Zhao \\ Suzhou Sano Precision Medicine Ltd \\ Changjun Shi \\ Suzhou Sano Precision Medicine Ltd \\ Sheng Xiao \\ Brigham and Women's Hospital \\ Jun Dong ( $\nabla$ dongjun@suda.edu.cn ) \\ Second Affiliated Hospital of Soochow University
}

Case Report

Keywords: Gliosarcoma, Osteosarcoma, Biphasic differentiation, Metastasis, Target enrichment sequencing

Posted Date: November 17th, 2021

DOI: https://doi.org/10.21203/rs.3.rs-1060060/v1

License: @ (i) This work is licensed under a Creative Commons Attribution 4.0 International License. Read Full License

Version of Record: A version of this preprint was published at Pathology - Research and Practice on March 1st, 2022. See the published version at https://doi.org/10.1016/j.prp.2022.153837. 


\section{Abstract}

Background: Gliosarcoma (GS) represents a rare variant of glioblastoma in the central nervous system, characterized by biphasic histopathological features of gliomatous and sarcomatous components. Here, we present an unusual case of GS, which also demonstrated osteosarcomatous component.

Case presentations: The patient underwent gross total resection (GTR) of right temporal lobe lesion. Subsequently received external beam radiation therapy with $60 \mathrm{~Gy}$ and chemotherapy, postoperatively. The sarcomatous portion of the typical fibrosarcoma pattern mingled with areas of osteoid structure in this $65-$ year-old feminine case. The molecular pathological analysis demonstrated IDH1/2 wild-type and MGMT promoter island methylated phenotype. Target Enrichment Sequencing (TES) was performed on the gliomatous and sarcomatous components of the tumor tissues. TERT promoter, RB1, NF1, TP53 mutations and copy number variations (CNVs) on chromosome 7, 10q, 11q, 12, 13, 17 and 22 were observed in gliomatous and fibro-sarcomatous mixed tumor tissue; While we found TERT promoter, RB1, TP53 mutations and CNVs on chromosome 2q, 3q, 7, 8, 9, 10, 11, 12, 13, 15, 16, 17, 18, 19 and 22 in osteosarcomatous tumor tissue. Noteworthy, EGFR amplification was not observed in both gliomatous and sarcomatous tumor tissues.

Conclusions: In conclusion, integrated with histopathology, molecular pathology, and genomic alteration analysis, we report a case of GS with an extremely rare histopathologic phenotype of osteosarcomatous differentiation, also suffered lung multi-metastases. Additionally, by reviewing the literature, our study of this unusual differentiation of GS into osteosarcoma provides novel insight into the natural history of GS.

\section{Background}

Gliosarcoma (GS) represents a rare type of malignant neoplasm in the central nervous system (CNS)[1], comprising both gliomatous and sarcomatous components. In 2016 WHO classification of tumors of CNS, GS was defined as a subtype of IDH wild-type glioblastoma multiforme (GBM)[2]; While GS was not listed in the 2021 WHO classification, but referred to as a classic variant of GBM[3]. GS was originally described by Stroebe in 1895. And in 1955, Feigin[4] defined GS as a variant of GBM, characterized by a neoplastic transformation in the proliferating vessels. Hence, we sometimes referred to GS as "Feigin's tumor". It was estimated that GS accounted for approximately $2 \%$ of GBM[5, 6].

The gliomatous component in GS usually exhibits typical feature of glioblastoma, or occasionally shows oligodendroglial characteristic[7, 8]. While sarcomatous component is most frequently represented by a fibrosarcoma. However, other patterns resembling angiosarcoma[9], rhabdomyosarcoma[10], or pleomorphic sarcoma[11] can also be encountered. Cases of GS with osteosarcomatous components are extremely rare. Till date, only quite a few cases of GS consisted with osteosarcomatous differentiated component have been reported, previously[1, 12-18]. This specific type of GS can be divided into two subtypes: primary GS (pGS) and secondary GS (sGS). The pGS with osteosarcomatous component was de novo, and the diagnosis was confirmed after the initial operation[1, 12,19-21]. Additionally, there was no history of radiotherapy and no history of another organ osteosarcoma. While the sGS with osteosarcomatous component always shared a history of external beam radiation therapy after intracranial malignant neoplasm surgery[16, 18]. It was speculated that the osteosarcomatous component might arise as a radiation-induced malignance transformation, which was consistent with previous reports, post-irradiation GS accounted for a considerable proportion of total GS[6, 15].

In this article, we report a case of GS with osteosarcomatous component. Due to the exceeding rare incidence of this type of mesenchymal differentiation in GS, we integrated conventional histopathology, molecular pathology, and Target Enrichment Sequencing (TES) data. And we conducted a comprehensive analysis of this case. Furthermore, a thorough literature review was performed to deep insight into the etiology and pathological characteristics of GS with this specific mesenchymal component.

\section{Case Presentation}

A 65-year-old female patient with a history of more than 10 days holo-cranial headache, drowsiness, gait imbalance, muscle power weakness of left limbs, and other neurological deficits were excluded. T2 weighted magnetic resonance imaging (MRI) of the brain revealed a massive inhomogeneous lesion located in the right temporal lobe, measuring $4.8 \times 3.6 \times 4.3 \mathrm{~cm}$ in dimension, with extensive peri-tumoral edema extending up to parietal cortex (Figure $1 \mathrm{~A}$ ). Contrastenhanced MRI exhibited a right temporal lobe irregular rosette enhancing mass (Figure 1B). Computed tomography (CT) scan revealed scattered calcific density lesions abutting right middle skull base (Figure 1C).

We operated upon the patient after the full preoperative planning, and postoperative MRI revealed that the tumor was grossly resected (Figure 2A, B). During the surgery, it was observed that intra-temporal lobe tumor tissue was very similar to gliomatous tissue with invasive growth, abundant blood supply, and drab yellow under the surgical microscope. But nearly $1 / 3$ of the tumor tissue abutting the middle cranial fossa dura was firm, well-demarcated, closely adhere to the dura mater, and accompanied by skull base bone invasion, resembling meningiomas. The tumor tissues were subjected to histo and molecular pathological examination. The patient was given a course of external beam radiation therapy with a total of 60 Gy, subsequently. Reviewed MR scan at 11 months after the surgery, enhanced-T1 weighted imaging showed novel nodular enhancements bordering on right middle cranial fossa dura (Figure 2C), which was consistent with tumor recurrence. CT imaging revealed calcific density lesions located in the recurrent area (Figure 2E). Subsequent sequential or alternating administrated temozolomide, tyrosine kinase inhibitor (TKI, Anlotinib), and an immune checkpoint inhibitor (PD-1 inhibitor, Camrelizumab). A reviewed MR scan 2 months after the novel protocol implementation revealed that the gross tumor volume (GTV) of the recurrent tumor was significantly regressed (Figure 2D). However, calcific lesions showed poor response for novel adjuvant therapy regimens, following CT scanning indicated a gradually enlarged volume of recurrent calcification (Figure 2F). However, the patient faced a new challenge, simultaneously. The chest CT scanning revealed multiple lesions scattered in the lung of bilateral sides (Figure $2 \mathrm{G}$ ). The lung lesions showed multiple dissemination and regular morphology, which is consistent with the radiology characteristics of metastases. 
Histopathological examination of the soft tumor tissue revealed a biphasic histologic pattern, which displayed both gliomatous and sarcomatous components (Figure 3A, B). Immunohistochemical analysis indicated partial expression of GFAP, high expression of TP53 in whole tumor tissue, partial expression of microglial/macrophage marker CD68, and high expression of mesenchymal cells marker Vimentin in sarcomatous component (Figure 3C-F). However, histopathological analysis of the firm lesions scattered inside the tumor revealed osteosarcomatous component and osteoid structure (Figure $3 \mathrm{G}$ ). Immunohistochemical analysis of this component presented reactivity with Special AT-rich sequence-binding protein 2 (SATB2) and Vimentin (Figure H, I), and GFAP expression was excluded. Molecular pathological analysis verified IDH1/2 wild-type in both soft and firm lesions, and MGMT promoter island methylated (Method: Methylation-Specific PCR, MSP) (Figure 4A). However, further comparative analysis of the TES (Method: 638 genes panel) (Platform: Illumina Novaseq 6000) data from soft and firm fresh tumor tissues was summarized in Table 1. We found that somatic mutations of soft tissues occurred in TERT promoter (c.-146 C>T), RB1, TP53, and NF1. While TERT promoter (c.-146 C>T), RB1, and TP53 somatic mutations were also observed in firm tumor tissue, except for NF1. Copy number variation (CNV) analysis of soft tumor tissue implied that gain on chromosome 7, losses on chromosomes 11q, 12, 13 (RB1), and 22 (NF2), and copy neutral loss of heterozygosity (LOH) on chromosomes 10q and 17. However, CNVs were more frequent in firm tumor tissue, involving gains on chromosomes $3 q$ and 7, losses on chromosomes 10 (PTEN), 11, 12, 13 (RB1), and 17 (NF1 and TP53), and copy neutral LOH on chromosomes 2q, 8, 9, 15, 16, 18, 19 and 22. (Figure 4B). Nevertheless, EGFR gene amplification was not observed in soft or firm tumor tissues, while gain on chromosome 7 (Figure 4C). Comprehensive analysis of tumor mutation burden (TMB) showed a relatively low level ( 1.28 mutants/Mb in soft, 0.64 mutants/Mb in firm).

Table 1

Summary of the somatic alterations.

\begin{tabular}{|c|c|c|}
\hline Variation & Soft tumor tissues & Firm tumor tissues \\
\hline \multirow[t]{4}{*}{ Mutations } & TERTp, c. $-146 \mathrm{C}>\mathrm{T}, 31 \%$ & TERTp, c. $-146 \mathrm{C}>\mathrm{T}, 26.9 \%$ \\
\hline & RB1, c. $1049+1 G>A, 37.0 \%$ & RB1, c. $1049+1 G>A, 44.8 \%$ \\
\hline & TP53, c.730G>A, p.G244S, 53.9\% & TP53, c.730G>A, p.G244S, 43.0\% \\
\hline & NF1, c. $3708 \mathrm{G}>\mathrm{A}$, p.W1236X, 51.0\% & \\
\hline \multirow[t]{3}{*}{ CNVs } & Gain: chr 7 & Gain: chr 3q, 7 \\
\hline & Loss: chr 11q, 12, 13, 22 & Loss: chr 10, 11, 12, 13, 17 \\
\hline & CN-LOH: 10q, 17 & CN-LOH: 2q, 8, 9, 15, 16, 18, 19, 22 \\
\hline TMB (muts/Mb) & 1.28 & 0.64 \\
\hline
\end{tabular}

\section{Discussion And Conclusions}

A retrieved result from Web of Science, PubMed, and Medline databases since 1950, with the terms gliosarcoma and osteosarcomatous/osteoid, only articles published in English with essential information of the cases were included. We collected 13 cases of GS with osteosarcomatous differentiation[1, 12, 22, 23, 13-18, 20, 21]. As exhibited in Table 2, patient information, clinical features, calcific lesions, treatments, overall survival times, and extracranial metastatic information of the cases were included. 
Table 2

Literature summary of GS with osteosarcomatous component cases since 1950.

\begin{tabular}{|c|c|c|c|c|c|c|c|c|c|c|c|}
\hline \multirow{2}{*}{$\begin{array}{l}\text { Authors } \\
\text { (dates) }\end{array}$} & \multicolumn{2}{|c|}{$\begin{array}{l}\text { Patient } \\
\text { information }\end{array}$} & \multicolumn{3}{|l|}{ Clinical features } & \multicolumn{2}{|c|}{ Calcific lesions } & \multirow[t]{2}{*}{ Treatments } & \multirow[t]{2}{*}{$\begin{array}{l}\text { OS } \\
\text { (months) }\end{array}$} & \multirow[t]{2}{*}{$\begin{array}{l}\text { Mol. } \\
\text { pathology }\end{array}$} & \multirow[t]{2}{*}{$\mathbf{E}$} \\
\hline & $\begin{array}{l}\text { Age } \\
\text { (years) }\end{array}$ & Gender & $\begin{array}{l}\text { Clinical } \\
\text { presentations }\end{array}$ & $\begin{array}{l}\text { Primary } \\
\text { GS }\end{array}$ & Location & Radiology & Macroscopy & & & & \\
\hline $\begin{array}{l}\text { Sarmiento et } \\
\text { al. (1979) }\end{array}$ & 49 & Female & Headache & Yes & $\begin{array}{l}\text { Lt. } \\
\text { Frontal }\end{array}$ & Yes & Yes & NA & NA & NA & $\uparrow$ \\
\hline $\begin{array}{l}\text { Tada et al. } \\
\text { (1987) }\end{array}$ & 56 & Male & NA & Yes & $\begin{array}{l}\text { Rt. } \\
\text { Temporal }\end{array}$ & Yes & NA & NA & NA & NA & $\uparrow$ \\
\hline $\begin{array}{l}\text { Paulus et al. } \\
\text { (1993) }\end{array}$ & 39 & Female & NA & No & $\begin{array}{l}\text { Temporal- } \\
\text { Parietal }\end{array}$ & Yes & Yes & $\mathrm{RT}+\mathrm{CT}$ & 11 & NA & $\uparrow$ \\
\hline $\begin{array}{l}\text { Hayashi et } \\
\text { al. (1993) }\end{array}$ & 55 & Male & $\begin{array}{l}\text { Headache/Memory } \\
\text { disturbance }\end{array}$ & Yes & $\begin{array}{l}\text { Lt. } \\
\text { Frontal }\end{array}$ & Yes & Yes & $\mathrm{RT}+\mathrm{CT}$ & 12 & NA & $\uparrow$ \\
\hline $\begin{array}{l}\text { Malone et al. } \\
\text { (1999) }\end{array}$ & 46 & Male & Blackouts & Yes & $\begin{array}{l}\text { Lt. } \\
\text { Frontal }\end{array}$ & Yes & Yes & RT & 4 & NA & $\uparrow$ \\
\hline $\begin{array}{l}\text { Lieberman et } \\
\text { al. (2001) }\end{array}$ & 49 & Male & Headache & No & $\begin{array}{l}\text { Rt. } \\
\text { Frontal }\end{array}$ & Yes & Yes & RT & 24 & NA & $\uparrow$ \\
\hline $\begin{array}{l}\text { Alatakis et } \\
\text { al. }(2004)\end{array}$ & 53 & Female & Seizures & No & $\begin{array}{l}\text { Lt. } \\
\text { Parietal }\end{array}$ & Yes & Yes & $\mathrm{RT}+\mathrm{CT}$ & 24 & NA & $\uparrow$ \\
\hline $\begin{array}{l}\text { Schittenhelm } \\
\text { et al. (2007) }\end{array}$ & 65 & Female & $\begin{array}{l}\text { Headache/ } \\
\text { Cognitive decline }\end{array}$ & Yes & $\begin{array}{l}\text { Lt. } \\
\text { Temporal- } \\
\text { Occipital }\end{array}$ & NA & Yes & NA & NA & NA & $\uparrow$ \\
\hline $\begin{array}{l}\text { Barut et al. } \\
\text { (2009) }\end{array}$ & 52 & Male & Headache & No & $\begin{array}{l}\text { Rt. } \\
\text { Parietal }\end{array}$ & NA & Yes & $\mathrm{RT}+\mathrm{CT}$ & 10 & NA & $\uparrow$ \\
\hline $\begin{array}{l}\text { Barut et al. } \\
\text { (2009) }\end{array}$ & 69 & Male & Gait imbalance & Yes & $\begin{array}{l}\text { Rt. } \\
\text { Frontal }\end{array}$ & NA & Yes & NA & 3 & NA & $\uparrow$ \\
\hline $\begin{array}{l}\text { Charfi et al. } \\
(2009)\end{array}$ & 33 & Female & $\begin{array}{l}\text { Headache/Blurring } \\
\text { of vision }\end{array}$ & Yes & $\begin{array}{l}\text { Lt. } \\
\text { Parietal }\end{array}$ & Yse & Yes & No & 9 & NA & Y \\
\hline $\begin{array}{l}\text { Tyagi et al. } \\
(2013)\end{array}$ & 57 & Male & Dizziness/Seizures & Yes & $\begin{array}{l}\text { Lt. } \\
\text { Temporal }\end{array}$ & NA & Yes & CT & NA & NA & $\uparrow$ \\
\hline \multirow[t]{2}{*}{$\begin{array}{l}\text { Yoshida et } \\
\text { al. (2018) }\end{array}$} & 51 & Male & Malaise & Yes & $\begin{array}{l}\text { Rt. } \\
\text { Frontal }\end{array}$ & NA & Yes & $\mathrm{RT}+\mathrm{CT}$ & $>20$ & $\begin{array}{l}\text { IDH1/2- } \\
\text { WT }\end{array}$ & $\uparrow$ \\
\hline & & & & & & & & & & TERT-Mut & \\
\hline
\end{tabular}

Abbreviations: RT. Radiotherapy; CT. Chemotherapy; EM. Extracranial metastasis; OS. Overall survival; GS. Gliosarcoma; Mol. Molecular; NA. No available; Lt. Light; Rt. Right; WT. Wildtype; Mut. Promoter Mutant

Twelve articles and 13 cases of GS with osteosarcomatous features were included for this retrospective study. Sex distribution (Male vs. Female; 8:5). The age when diagnosed with the disease ranged from 33 to 69 years old, with the mean age $51.85 \pm 9.17$. The most common clinical presentations were headache, epilepsy, and focal neurological dysfunction, with no specific clinical manifestations. Among them, 9 pGS cases and 4 sGS cases (all 4 sGS cases were derived from various intracranial malignant neoplasm, with a history of radiation therapy). Calcifications can be observed in almost all cases of preoperative CT scans, with varying ranges. Nevertheless, histopathological analysis discovered osteosarcomatous component is the golden criteria for the diagnosis of this specific type of GS. In this series of cases, only one case completed tumor molecular pathology analysis, which demonstrated IDH1/2 wild-type and TERT promoter mutant phenotype. Except for an extradural tumor progression with cutaneous permeation in one case, no extracranial metastasis of this specific type of GS was reported during the progression of disease.

Osteosarcomatous differentiation rarely occurs in sarcomatous component of GS. As mentioned above, only a quite few case reports can be retrieved. Till date, the etiology of this specific type of GS is not displayed. Radiological calcifications of pre-operative CT scans and post-operative pathological features are helpful for diagnosing this unusual type of differentiation in GS. The GS with osteosarcomatous feature may arise from supratentorial cerebral hemispheres of various parts, usually locates in the cerebral cortex, abutting dura mater and resembling meningiomas[24, 25].

Although there is no obvious difference between GS and GBM in clinical presentations, radiological features, treatment strategy, and survival outcomes. GS shares a much higher tendency of extracranial metastases than GBM[26]. The approximate occurrence of GS extracranial metastasis is 11\%[27]. GS extracranial metastases are mostly located in the lungs and liver, and dissemination within neuraxis is uncommon even have been reported[25]. Although the mechanism of GS extracranial metastasis remains controversial, one assumption is that the history of craniotomy causes meningeal, skull and parenchymal blood vessel defects, which provide an opportunity for cancer cell dissemination[26]. One vital clue is that almost all extracranial metastases of GS occurred several months after craniotomy. In this article, we present an even rarely reported GS case with osteosarcomatous feature, which also occurred distance dissemination, verifying the metastatic potential of GSs.

Apart from specifical histopathological characteristics of GS, GS also inhibits numerous molecular pathological and genomic alterations. Molecular pathological classification of the case was referred to as IDH1/2 wild-type and MGMT promoter methylated. The previous report suggested that those 
alterations might be associated with epithelial to mesenchymal transition (EMT)[28]. A cohort comparative study has noted a lower frequency of EGFR copy number amplification in GS (8\%) than in GBM (up to 50\%)[29]. In our presented case, we unobserved EGFR copy number amplification both in soft and firm tumor tissues by analyzing TES data, which was consistent with the molecular characteristic of GS. Moreover, NF1 mutation was exclusively observed in soft tumor tissue. NF1 is a negative regulator of the Ras signal transduction pathway and a characteristic of the Mesenchymal subtype of GBM. Dysfunction of NF1 has been shown to facilitate EMT[30]. The above-mentioned molecular pathological and genomic alterations of our presented case were consistent with the characteristics of GS, high incidence of TP53 mutation and, rarely, EGFR and IDH1/2 mutations[31].

When we discuss the origin of multi-components in GS, whether monoclonal or polyclonal origin model? Which model is predominant in the GS formation? It remains controversial. Feigin[4] hypothetically suggested that sarcomatous component of GS might be derived from the malignant transformation of vascular proliferation, which actually represented a kind of polyclonal origin hypothesis. However, recent transcriptional and genomic studies preferred to support the monoclonal formation of GS, in which gliomatous and sarcomatous components arise from a common precursor cell clone, differentiating divergently toward gliomatous and sarcomatous subclones[13, 32, 33]. In our study, DNA sequencing revealed TERT promoter mutation (c.-146 C>T) in both soft and firm tumor tissues. Oh et al. also reported that TERT promoter mutations were detected in $83 \% \mathrm{GS}$, and that TERT promoter mutations were detected in $19 / 20$ glial and mesenchymal components of GS, respectively[32]. Additionally, the TES data from soft and firm tumor tissues in our presented case also showed high similarities. All the above-mentioned evidence validates the hypothesis of the monoclonal origin of GS.

In conclusion, we exhibit a rare case of GS with osteosarcomatous differentiation, which includes comprehensive histopathology, molecular pathology, and genomic alteration analysis. Together with reviewed literature, our study of the unusual differentiation of GS into osteosarcoma provides novel insight into the natural history of GS and indirectly about the natural history of glioblastoma.

\section{Abbreviations}

GS

Gliosarcoma

GTR

Gross total resection

TES

Target Enrichment Sequencing

CNVs

Copy number variations

CNS

Central nervous system

GBM

Glioblastoma multiforme

pGS

Primary GS

sGS

Secondary GS

MRI

Magnetic resonance imaging

CT

Computed tomography

TKI

Tyrosine kinase inhibitor

SATB2

Special AT-rich sequence-binding protein 2

MSP

Methylation-Specific PCR

$\mathrm{LOH}$

Loss of heterozygosity

TMB

Tumor mutation burden

EMT

epithelial to mesenchymal transition.

\section{Declarations}

\section{Ethics approval and consent to participate}

The study was approved by the ethics committee of The Second Affiliated Hospital of Soochow University.

\section{Consent for publication}


Written informed consent for publication of the clinical details and clinical images was obtained from the relative of patient.

\section{Availability of data and materials}

Not applicable.

\section{Competing interests}

The authors declared no conflict of interest.

\section{Funding}

This study was funded by the National Natural Science Foundation of China (81602183), Clinical Special Disease Diagnosis and Treatment Technology in Suzhou (LCZX201807), Key Project of Jiangsu Health Commission (ZDB2020016), and Natural Science Foundation of Jiangsu Province (BK20201172).

\section{Authors' contributions}

Yanming Chen and Jun Dong designed this study. Sujuan Zhou, Xiaoxiao Dai, Ping Chen, Shengbin Zhao, Changjun Shi and Sheng Xiao were responsible for pathological diagnosis and immunohistochemical experiments. Xuelan Zhou and Liping Wang supported clinical data. Jun Dong and Ping Chen guided this work. All authors approved the final version of the submitted manuscript.

\section{Acknowledgements}

Not applicable.

\section{References}

1. Hayashi K, Ohara N, Jeon HJ, Akagi S, Takahashi K, Takahashi K, et al. Gliosarcoma with features of chondroblastic osteosarcoma. Cancer [Internet]. 1993;72:850-5. Available from: https://onlinelibrary.wiley.com/doi/10.1002/1097-0142(19930801)72:3\%3C850::AID-CNCR2820720334\%3E3.0.C0;2-4

2. Louis DN, Perry A, Reifenberger G, von Deimling A, Figarella-Branger D, Cavenee WK, et al. The 2016 World Health Organization Classification of Tumors of the Central Nervous System: a summary. Acta Neuropathol [Internet]. 2016;131:803-20. Available from: http://link.springer.com/10.1007/s00401-0161545-1

3. Louis DN, Perry A, Wesseling P, Brat DJ, Cree IA, Figarella-Branger D, et al. The 2021 WHO Classification of Tumors of the Central Nervous System: a summary. Neuro Oncol. 2021;23:1231-51.

4. FEIGIN IH, GROSS SW. Sarcoma arising in glioblastoma of the brain. Am J Pathol [Internet]. 1955;31:633-53. Available from: http://www.ncbi.nlm.nih.gov/pubmed/14388124

5. Galanis E, Buckner JC, Dinapoli RP, Scheithauer BW, Jenkins RB, Wang CH, et al. Clinical outcome of gliosarcoma compared with glioblastoma multiforme: North Central Cancer Treatment Group results. J Neurosurg [Internet]. 1998;89:425-30. Available from: https://thejns.org/view/journals/jneurosurg/89/3/article-p425.xml

6. Perry JR, Ang LC, Bilbao JM, Muller PJ. Clinicopathologic features of primary and postirradiation cerebral gliosarcoma. Cancer [Internet]. 1995;75:2910-8. Available from: https://onlinelibrary.wiley.com/doi/10.1002/1097-0142(19950615)75:12\%3C2910::AID-CNCR2820751219\%3E3.0.CO;2-A

7. Feigin I, Ransohoff J, Lieberman A. Sarcoma Arising in Oligodendroglioma of the Brain. J Neuropathol Exp Neurol [Internet]. 1976;35:679-89. Available from: https://academic.oup.com/jnen/article-lookup/doi/10.1097/00005072-197611000-00005

8. Tanaka S, Hitotsumatsu T, Sugita Y, Ishido K, Ito O, Hatae R, et al. Gliosarcoma arising from oligodendroglioma (Oligosarcoma): A case report with genetic analyses. Pathol Int. 2018;68:567-73.

9. Shintaku M, Miyaji K, Adachi Y. Gliosarcoma with angiosarcomatous features: A case report. Brain Tumor Pathol [Internet]. 1998;15:101-5. Available from: http://link.springer.com/10.1007/BF02478891

10. Barnard RO, Bradford R, Scott T, Thomas DGT. Gliomyosarcoma. Report of a case of rhabdomyosarcoma arising in a malignant glioma. Acta Neuropathol [Internet]. 1986;69:23-7. Available from: http://www.ncbi.nlm.nih.gov/pubmed/3962596

11. Ng HK, Poon WS. Gliosarcoma of the posterior fossa with features of a malignant fibrous histiocytoma. Cancer [Internet]. 1990;65:1161-6. Available from: https://onlinelibrary.wiley.com/doi/10.1002/1097-0142(19900301)65:5\%3C1161::AID-CNCR2820650522\%3E3.0.CO;2-F

12. Sarmiento J, Ferrer I, Pons L, Ferrer E. Cerebral mixed tumour: osteo-condrosarcomaglioblastoma multiforme. Acta Neurochir (Wien) [Internet]. 1979;50:335-41. Available from: http://link.springer.com/10.1007/BF01808532

13. Yoshida Y, Ide M, Fujimaki H, Matsumura N, Nobusawa S, Ikota H, et al. Gliosarcoma with primitive neuronal, chondroid, osteoid and ependymal elements. Neuropathology. 2018;38:392-9.

14. Malone JC, Brown KZ, Parker JC. Pathologic Quiz Case. Arch Pathol Lab Med [Internet]. 1999;123:358-60. Available from: https://meridian.allenpress.com/aplm/article/123/4/358/452204/Pathologic-Quiz-Case

15. Barut F, Onak Kandemir N, Ozdamar SO, Gul S, Bektas S, Dogan Gun B, et al. Gliosarcoma with Chondroblastic Osteosarcomatous Differentation: Report of Two Case with Clinicopathologic and Immunohistochemical Features. Turk Neurosurg. 2009;19:417-22.

16. Schittenhelm J, Erdmann T, Maennlin S, Will BE, Beschorner R, Bornemann A, et al. Gliosarcoma with chondroid and osseous differentiation. Neuropathology [Internet]. 2007;27:90-4. Available from: https://onlinelibrary.wiley.com/doi/10.1111/j.1440-1789.2006.00747.x 
17. Alatakis S, Stuckey S, Siu K, McLean C. Gliosarcoma with osteosarcomatous differentiation: Review of radiological and pathological features. J Clin Neurosci. 2004;11:650-6.

18. Lieberman KA, Fuller CE, Caruso RD, Schelper RL. Postradiation gliosarcoma with osteosarcomatous components. Neuroradiology [Internet]. 2001;43:555-8. Available from: http://link.springer.com/10.1007/s002340000531

19. Tada T, Katsuyama T, Aoki T, Kobayashi S, Shigematsu H. Mixed glioblastoma and sarcoma with osteoid-chondral tissue. Clin Neuropathol [Internet]. 1987;6:160-3. Available from: http://www.ncbi.nlm.nih.gov/pubmed/3115659

20. Barresi V, Cerasoli S, Morigi F, Cremonini AM, Volpini M, Tuccari G. Gliosarcoma With Features of Osteoblastic Osteosarcoma: A Review. Arch Pathol Lab Med [Internet]. 2006;130:1208-11. Available from: https://meridian.allenpress.com/aplm/article/130/8/1208/459988/Gliosarcoma-With-Features-ofOsteoblastic

21. Tyagi I, Majumdar K, Mehta S, Batra V V. Gliosarcoma with osseous tissue: An occasional metaplastic component. Brain Tumor Pathol. 2013;30:40-4.

22. Charfi S, Ayadi L, Khabir A, Daoud E, Kallel R, Kharrat O, et al. Gliosarcoma with osteosarcomatous features: A short illustrated review. Acta Neurochir (Wien). 2009;151:809-13.

23. PAULUS W, JELLINGER K. Mixed glioblastoma and malignant mesenchymoma, a variety of gliosarcoma. Histopathology [Internet]. 1993;22:277-9. Available from: https://onlinelibrary.wiley.com/doi/10.1111/j.1365-2559.1993.tb00120.x

24. Kozak KR, Mahadevan A, Moody JS. Adult gliosarcoma: Epidemiology, natural history, and factors associated with outcome. Neuro Oncol. 2009;

25. Doddamani RS, Meena RK, Selvam MM, Venkataramanaa NK, Tophkhane M, Garg SK. Intraventricular Gliosarcomas: Literature Review and a Case Description. World Neurosurg [Internet]. Elsevier Ltd; 2016;90:707.e5-707.E12. Available from: http://dx.doi.org/10.1016/j.wneu.2016.03.033

26. Choi M-G, Lee J-H, Lee M-S, Suh S-J, Lee Y-S, Kang D-G. Primary Gliosarcoma with Extracranial Metastasis. Brain Tumor Res Treat. $2020 ; 8: 53$.

27. Beaumont TL, Kupsky WJ, Barger GR, Sloan AE. Gliosarcoma with multiple extracranial metastases: case report and review of the literature. J Neurooncol [Internet]. 2007;83:39-46. Available from: http://link.springer.com/10.1007/s11060-006-9295-x

28. Dardis C, Donner D, Sanai N, Xiu J, Mittal S, Michelhaugh SK, et al. Gliosarcoma vs. glioblastoma: a retrospective case series using molecular profiling. BMC Neurol. BMC Neurology; 2021;21:1-13.

29. Han SJ, Yang I, Tihan T, Prados MD, Parsa AT. Primary gliosarcoma: key clinical and pathologic distinctions from glioblastoma with implications as a unique oncologic entity. J Neurooncol [Internet]. 2010;96:313-20. Available from: http://link.springer.com/10.1007/s11060-009-9973-6

30. Baek ST, Tallquist MD. Nf1 limits epicardial derivative expansion by regulating epithelial to mesenchymal transition and proliferation. Development [Internet]. 2012;139:2040-9. Available from: https://journals.biologists.com/dev/article/139/11/2040/45143/Nf1-limits-epicardial-derivative-expansionby

31. Cachia D, Kamiya-Matsuoka C, Mandel JJ, Olar A, Cykowski MD, Armstrong TS, et al. Primary and secondary gliosarcomas: clinical, molecular and survival characteristics. J Neurooncol. 2015;125:401-10.

32. Oh JE, Ohta T, Nonoguchi N, Satomi K, Capper D, Pierscianek D, et al. Genetic Alterations in Gliosarcoma and Giant Cell Glioblastoma. Brain Pathol [Internet]. 2016;26:517-22. Available from: https://onlinelibrary.wiley.com/doi/10.1111/bpa.12328

33. Reis RM, Könü-Lebleblicioglu D, Lopes JM, Kleihues P, Ohgaki H. Genetic Profile of Gliosarcomas. Am J Pathol [Internet]. 2000;156:425-32. Available from: https://linkinghub.elsevier.com/retrieve/pii/S0002944010647463

\section{Figures}



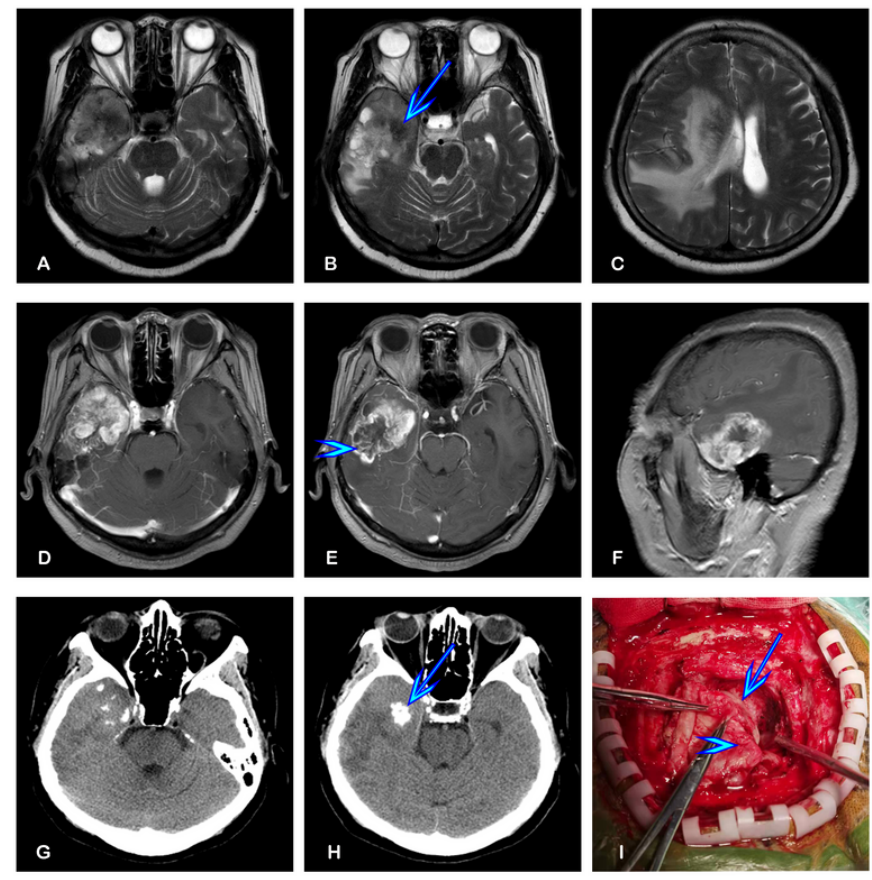

\section{Figure 1}

Preoperative neuroradiological and intraoperative images. (A-C) T2-weighted MRI revealed an inhomogeneous lesion in the right temporal lobe, with extensive peri-tumoral edema extending up to frontal-parietal lobe; (D-F) Enhanced T1-weighted MR images irregular rosette enhancing mass; (G, H) Plain CT (axial) showed patchy-calcified lesions in right temporal lobe; (I) intraoperative image revealed calcified component (firm tumor tissue) and soft tumor tissue. Blue arrow represents calcified component, and blue arrowhead represents soft tumor tissue. 

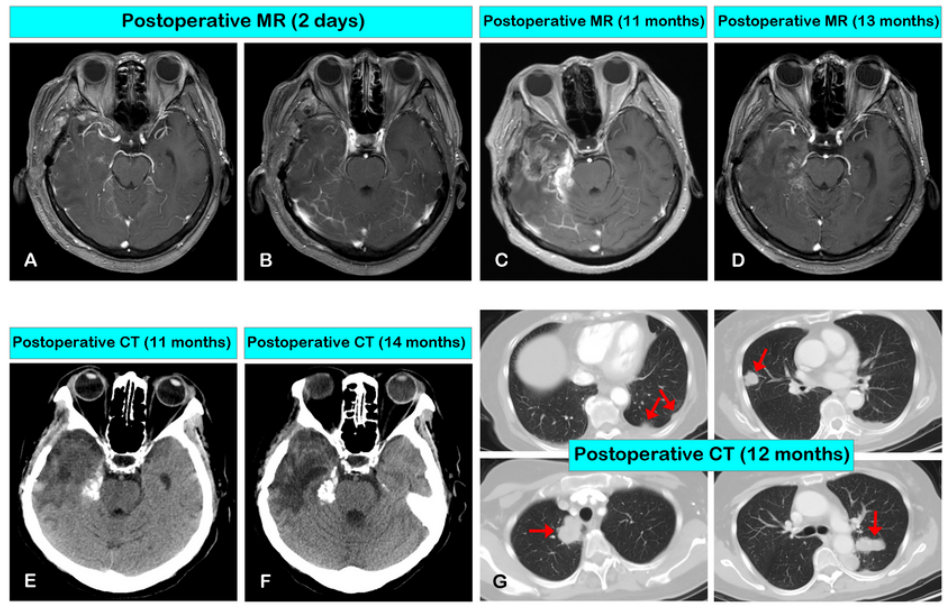

\section{Figure 2}

Postoperative radiological images. (A, B) Enhanced T1-weighted MR images revealed that the tumor was grossly resected 2 days after the craniotomy; (C) Enhanced T1-weighted imaging showed a recurrent tumor occupying the tumor-resected cavity 11 months after the craniotomy; (D) MR imaging indicated the recurrent tumor was significantly regressed 2 months after the novel adjuvant therapy; (E) CT scanning revealed calcified lesion mixed in intracranial recurrent tumor 11 months after the surgery; (F) Reviewed CT image indicated that calcified lesion from recurrent tumor showed poor response to novel adjuvant therapy; (G) Chest CT scanning revealed multi-lesions scattered in the pleura and lung of bilateral sides (Red arrows). 


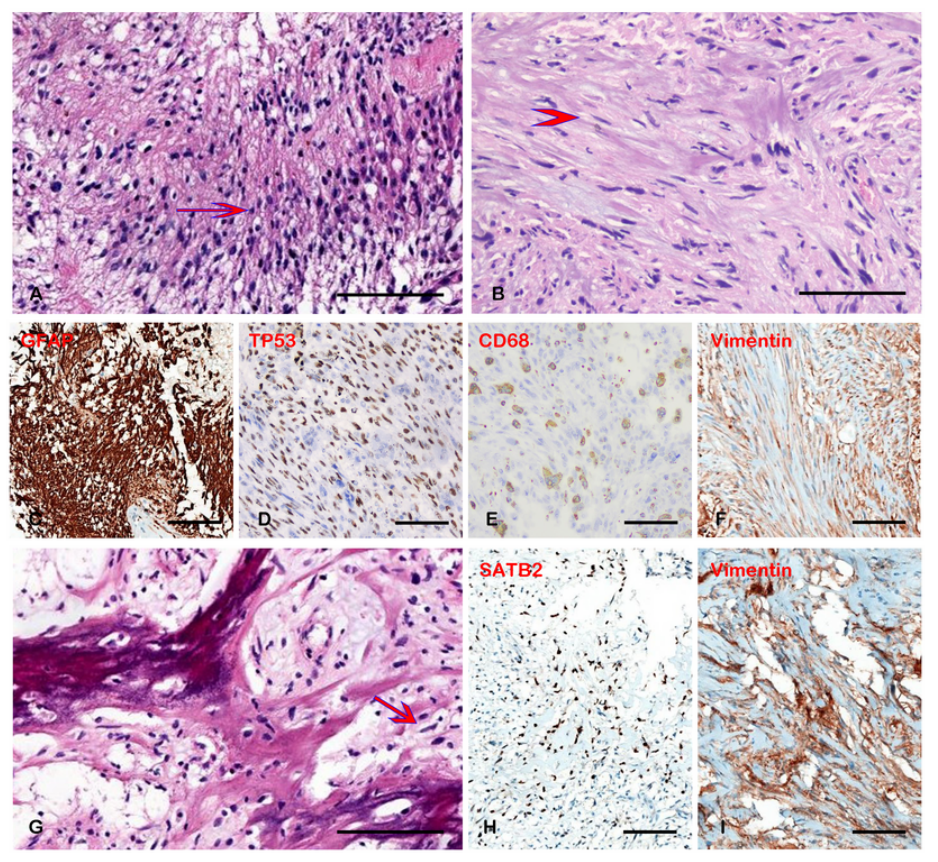

\section{Figure 3}

Histopathological analysis of the brain tumor specimen revealed multi-components intra-tumor. (A, B) H\&E staining of soft tumor portion shows gliomatous (Red arrow) and sarcomatous (Red arrowhead) components; (C) Immunohistochemical staining showing partial glial differentiation; (D) TP53 staining showing positivity expression; (E) Stain for CD68 protein showing partial expression; (F) Immunohistochemistry for Vimentin highlighting the sarcomatous component; (G) H\&E staining of calcified component shows osteosarcomatous component (Red arrow); (H) STAB2 staining shows osteosarcomatous differentiation in calcified tumor specimen; (I) Vimentin staining displays mesenchymal components in firm tumor tissue. Scale bar $=100 \mu \mathrm{m}$ 

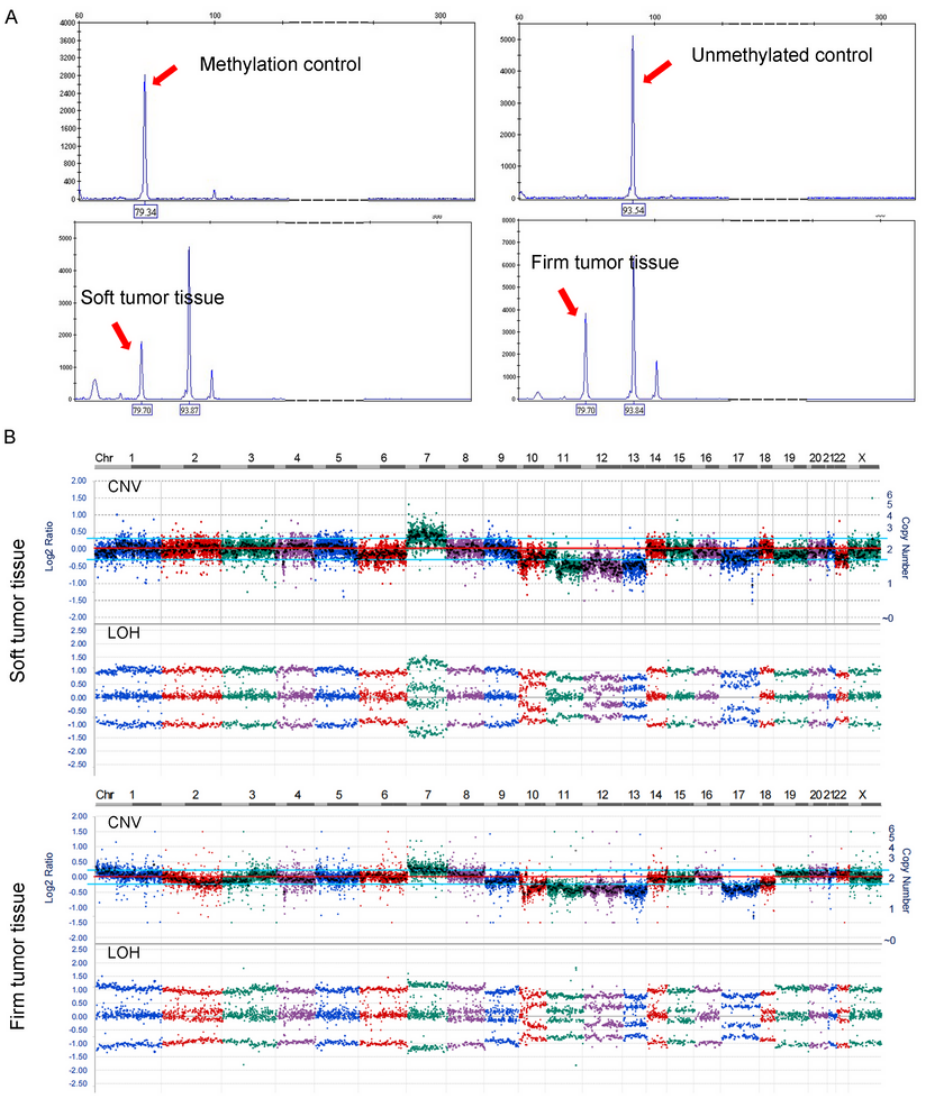

C

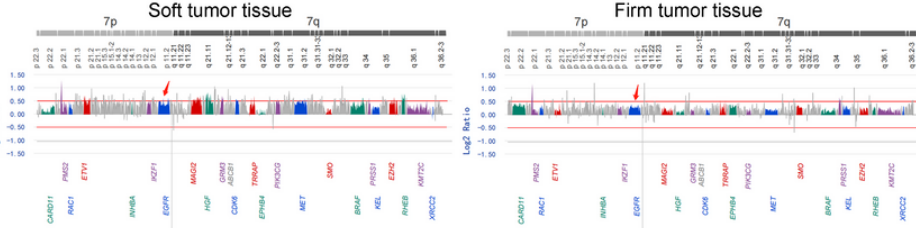

\section{Figure 4}

Molecular pathology and genomic alteration analysis. (A) MGMT promoter island methylation was detected both in soft and firm tumor tissues; (B) CNV analysis of soft tumor tissue and firm tumor tissue, respectively; (C) EGFR (Red arrow) amplification was not observed in chromosome 7. 